Session 12-20

\title{
Postsurgical Finite Element Analysis of Mandibular Fracture Fixation
}

\author{
Scott T. Lovald, Tariq Khraishi \\ Mechanical Engineering Dept., University of New Mexico \\ Jon Wagner, Bret Baack \\ Department of Surgery, University of New Mexico
}

\begin{abstract}
Surgeons often supplement surgeries involving rigid internal fixation of mandibular fractures with a short postoperative period of intermaxillary fixation (IMF) to allow a few weeks of healing in the fracture region before normal patient functioning is allowed. It is believed that this could reduce the likelihood of complications in some patients. A finite element model of a mandible with a parasymphyseal fracture was created and anatomically loaded to determine the effect of fracture healing on the occurrence of complications. Measures of strain in the fracture region, stress in the bone surrounding implant screws, and stress in the implant devices were measured while the stiffness in the fracture region was gradually increased to mimic fracture healing. According to the results of the FEA, delaying normal patient functioning with IMF for two weeks decreases the first principal strain in the fracture region to $54 \%$ of its immediate postoperative value. Over the same time period peak Von Mises stress in the cortical bone surrounding the screws and peak Von Mises stress in the plate were decreased to $62 \%$ and $60 \%$ of their original values, respectively.
\end{abstract}

\section{Introduction}

Rigid internal fixation is the standard method for treating mandibular fractures. Complications from this surgery are significant and include nonunion, malunion, and delayed union of the fracture, as well as infection, and hardware failure. Craniomaxillofacial (CMF) surgeons will often use intermaxillary fixation (IMF) immediately following surgery to allow healing along the fracture before normal functioning is resumed ${ }^{3,15,4}$. The use of and the appropriate length of time for postoperative IMF has until now been determined entirely at the surgeon's discretion. The use of postoperative IMF is widely considered beneficial although excessively prolonged periods of IMF can lead to patient non-compliance and delayed healing in some individuals ${ }^{16}$.

Bolourian recently studied the clinical effect of two weeks IMF on clinical outcomes for patients with mandibular fractures ${ }^{3}$. Of 31 patients treated intraorally with miniplate fixation, primary bone healing was achieved in all cases and no major complications were recorded. The study reported not only improved complication rates compared to other 
outcomes recorded in previous studies, but improved rates compared to documented studies at the same institution with shorter periods of required IMF. The authors suggest that the 2 week period of IMF served to allow the reattachment of the soft tissue drape and the settling of the occlusion, while there was no investigation into the effect of initial healing on the biomechanics of the mandibular fracture region and the hardware used for the fixation system.

Finite Element (FE) modeling can offer insight into the stress and strain state of mandibular bone and fixation hardware when subjected to normal clinical loading. FE modeling is an appropriate tool to attempt to correlate stress and strain results to clinical outcomes. FE models of the human mandible have previously been developed to determine the effectiveness of implants used in mandibular fracture fixation. In most cases, these models assume no interaction and no stiffness along the fracture surfaces, assuming a fracture environment with no rigidity that is only valid in actuality for the immediate days after surgery, ${ }^{6,14,19}$. In reality the stiffness of the fracture region has been shown to be continuously changing from the properties of initial connective tissue to those of cortical bone. This entire process can take anywhere from 12 to 20 weeks. While good results can be obtained from FE models, the model conditions have a large effect on the pertinence of the conclusions for surgeons. Considering the frequent prescription of postoperative soft diet and intermaxillary fixation following internal fixation of mandibular fractures, the current challenge in mandibular modeling is to update the previous models to give surgeons a snapshot of model results for each stage in the fracture healing process.

The aim of this study is to understand the effect of increasing fracture stiffness on stress and strain measures determined through FE modeling and known to affect the occurrence of complications. An FE model of a mandible with a parasymphyseal fracture was created and anatomically loaded. Measures of strain in the fracture region, stress in the bone surrounding implant screws, and stress in the implant devices were measured while the stiffness in the fracture region was gradually increased to mimic fracture healing. These results examine the effect of delayed functioning on FE results and are ultimately intended to guide CMF surgeons towards appropriate lengths of IMF and soft diet suggestions. The current work is distinguished from prior works by having a CT-scan based, dentate, heterogeneously orthotropic, fully 3-D model of the mandible and the latest fracture fixation hardware coupled with the first finite-element modeling effort of bone healing.

\section{FEA Geometry Creation}

\section{Methods}

Computerized Tomography scans of a 22 year old male were obtained from a Siemens Somatone Sensations Multislice Scanner. The patient had full dentition and normal occlusion. The scans were imported into Mimics 7.3 (Materialise, Ann Arbor, MI) where thresholding and editing functions were used to create entities for cortical bone, cancellous bone, and the dental segment. IGES (Initial Graphics Exchange Specification) curves were approximated around the volumes and imported into ANSYS 8.0. Volumes 
were created and subsequently bonded in the symphysis, parasymphysis, body, angle, ramus, coronoid, and condyle regions using their respective IGES curves.

The volumes created were meshed using tetrahedral-shaped solid elements. The final mesh of the mandible with hardware consisted of 67,434 elements and 107,352 nodes. Mesh refinement was used in the plate, screws, fracture region, and the surrounding cortical and cancellous regions until convergence of all pertinent measures was established. A consistent mesh size was used in all analyses. Geometric information from the finite-element model was compared to the original CT scan data to ensure model validity. Furthermore, loadings similar to previous studies were mimicked in order to validate stress results. CAD model verification for this study was detailed in Chaudhary ${ }^{5}$ and Lovald ${ }^{14}$.

The fracture was simulated as a $2 \mathrm{~mm}$ thick linear fracture in the parasymphyseal region. A 3D Matrix miniplate is used to secure the fracture. Geometrical data for the plate was provided by the Stryker-Leibinger Corp (Kalamazoo, MI). There is a small amount of clearance between the modeled plate and bone, as in clinical situations. Unicortical screw fixation was used on the superior border while bicortical fixation was used on the inferior border. Screws were simulated as solid cylinders with a diameter of $2.3 \mathrm{~mm}$ that were inserted and bonded using Boolean functions into the bone material.

\section{Material Properties}

The finite-element model of the dentate mandible consists of the following materials: cortical bone, cancellous bone and dental segment (dentin, enamel, peridontal ligament). Coordinate systems and orthotropic properties for cortical bone only were designated in each of 12 mandibular volumes created and mentioned previously. Table 1 gives the material properties used in this study. The orthotropic cortical bone values were taken from a study by Schwartz-Dabney ${ }^{17}$. Isotropic properties for cancellous bone were taken from $\mathrm{An}^{1}$. The properties for dentin were taken from another FE study ${ }^{12}$, but correlate well with a study by Craig and Peyton ${ }^{7}$. In the current study only material properties for dentin are modeled in the dental segment due to its high modulus of elasticity. The properties of titanium plates and screws were taken from another FE study of mandibular angle fractures ${ }^{6}$.

\begin{tabular}{|c|c|c|c|c|c|c|c|c|c|}
\hline $\begin{array}{c}\text { Material } \\
\text { Properties }\end{array}$ & Symphysis & Parasymphysis & Angle & Ramus & Condyle & Coronoid & Cancellous & Dentin & Titanium \\
\hline $\mathbf{E}_{\mathbf{x}}$ & 20,492 & 21,728 & 23,793 & 24,607 & 23,500 & 28,000 & 10,400 & 17,600 & 110,000 \\
\hline $\mathbf{E}_{\mathbf{y}}$ & 12,092 & 12,700 & 12,757 & 12,971 & 12,650 & 14,000 & 10,400 & 17,600 & 110,000 \\
\hline $\mathbf{E}_{\mathbf{z}}$ & 16,350 & 17,828 & 19,014 & 18,357 & 17,850 & 17,500 & 10,400 & 17,600 & 110,000 \\
\hline $\mathbf{V}_{\mathbf{x y}}$ & 0.43 & 0.45 & 0.41 & 0.38 & 0.32 & 0.28 & 0.3 & 0.34 & 0.34 \\
\hline $\mathbf{V}_{\mathbf{y z}}$ & 0.22 & 0.2 & 0.22 & 0.23 & 0.25 & 0.28 & 0.3 & 0.34 & 0.34 \\
\hline $\mathbf{V}_{\mathbf{x z}}$ & 0.34 & 0.34 & 0.3 & 0.28 & 0.24 & 0.23 & 0.3 & 0.34 & 0.34 \\
\hline $\mathbf{G}_{\mathbf{x y}}$ & 5,317 & 5,533 & 5,493 & 5,386 & 5,500 & 5,750 & 4,000 & 6,567 & 41,045 \\
\hline $\mathbf{G}_{\mathbf{y z}}$ & 4,825 & 5,083 & 4,986 & 5,014 & 5,150 & 5,300 & 4,000 & 6,567 & 41,045 \\
\hline $\mathbf{G}_{\mathbf{x z}}$ & 6,908 & 7,450 & 7,579 & 7,407 & 7,150 & 7,150 & 4,000 & 6,567 & 41,045 \\
\hline
\end{tabular}

Table 1. Material properties used in FEA of the mandible. Orthotropic properties were used for cortical 
bone, while isotropic properties were used for cancellous bone, dentin, and the titanium plate. The $\mathrm{x}-$ direction is along the length of the mandible, the y-direction is normal to the bone plane, and the z-direction is their cross product.

Table 2 gives Young's Modulus determined for fracture stiffness at 0 , 4, and 8 weeks ${ }^{10}$. While the fracture healing reference gives numbers for fracture stiffness up to 16 weeks, it is rare that IMF is used to supplement rigid internal fixation past eight weeks. While this reference determined the stiffness of a fractured tibia, the final modulus given for $100 \%$ matured bone of the peripheral fracture tissue matches well with cortical bone modulus of elasticity of mandibular bone ${ }^{17}$. For the first eight weeks of healing in Table 2 , we have fitted the modulus values for the peripheral and central tissue, using least squares regression analysis, to an exponential curve $\left(r^{2}=0.94\right.$ and 0.91 for the peripheral and central tissue, respectively). A command/data input file was written for the original analysis and then iterated over the modulus of elasticity of the $2 \mathrm{~mm}$ thick fracture region/callus through ANSYS's Batch Mode. Poisson's Ratio for the fracture region is 0.3 for all analyses. Figure 1 shows the meshed mandibular model with its different material sections.

\begin{tabular}{|c|c|c|}
\hline & Central Tissue & Peripheral Tissue \\
\hline Stage (weeks) & Modulus (MPa) & Modulus (MPa) \\
\hline 0 & 0.05 & 20 \\
\hline 4 & 0.19 & 76 \\
\hline 8 & 20 & 2000 \\
\hline
\end{tabular}

Table 2. Modulus of Elasticity for the fracture region's central and peripheral tissue over the entire healing period $^{10}$.

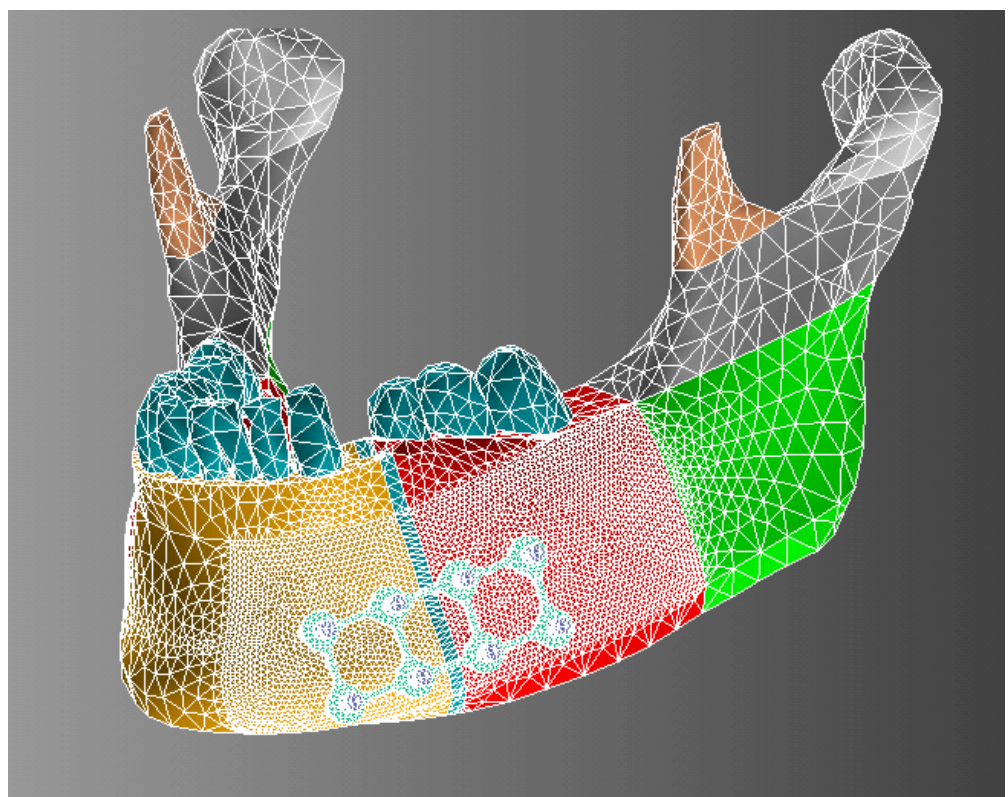

Figure 1. Meshed mandibular model showing fracture region, fixation hardware, and different material regions of cortical bone.

\section{Field Equations and Boundary Conditions}


The bite force used in this FEA was a unilateral molar clench. Muscle force vectors that were experimentally derived for that specific bite are then distributed around the mandible. Each force has a direction, area of attachment, and magnitude. Both condyles and the occlusal surface of the right first molar are restrained from movement in all directions.

The equations of equilibrium used in this mandibular FEA are:

$$
\sigma_{i j, j}+f_{i}=0, \quad i=1 . .3, j=1 . .3
$$

In the realm of small deformation theory, the strain $\varepsilon_{i j}$ at a material point is related to the gradients of displacement as follows:

$$
\varepsilon_{i j}=\frac{1}{2}\left(u_{i, j}+u_{j, i}\right), i=1 . .3, j=1 . .3
$$

For an orthotropic material deforming elastically, the stress-strain constitutive relation, or Hooke's Law, is as follows:

$$
\begin{aligned}
& \varepsilon_{i j}=\frac{1}{E_{i}} \sigma_{i i}-\frac{v_{j i}}{E_{j}} \sigma_{j j}-\frac{v_{k i}}{E_{k}} \sigma_{k k}, i=1 . .3, j=1 . .3, k=1 . .3 \\
& \varepsilon_{i j}=\frac{1}{2 G_{i j}} \sigma_{i j}, i=1 . .3, j=1 . .3
\end{aligned}
$$

where $E_{i}, G_{i j}$, and $v_{i j}$ are the different elastic material constants (9 total). In this last equation, a repeated index does not imply summation.

For an isotropic material, Hooke's Law reduces to two material constants (two from $G, \lambda$ and $v)$ :

$$
\varepsilon_{i j}=\frac{1}{2 G}\left(\sigma_{i j}-\frac{\lambda \delta_{i j}}{2 G+3 \lambda} \sigma_{k k}\right), i=1 . .3, j=1 . .3, k=1 . .3
$$

where

$$
\lambda=\frac{E v}{(1+v)(1-2 v)}
$$

Equations (1), (2), (3) and (4) apply to material elements in the whole mandibular domain, $\Omega$. Here $\sigma_{i j}$ is the $i j$ th component of the stress tensor, and $f_{i}$ is the $i$ th component of acting body forces. Body force contribution is negligible in this case.

The boundary conditions used in this mandibular FEA are:

$$
\begin{aligned}
& u_{i}=0, \quad i=1 . .3 \\
& \sigma_{i j} n_{j}=T_{i}, \quad i=1 . .3, j=1 . .3
\end{aligned}
$$

$u_{i}$ in Equation (5) is the $i$ th component of the displacement vector of a material point. The condition of zero displacement in Equation (5) applies to both condyle 
surfaces $\left(\Gamma_{\mathrm{C}}\right)$ and the occlusal surface of the first molar where the bite takes place $\left(\Gamma_{\mathrm{T}}\right)$. This bite restraint is applied contralateral to the fracture side of the mandible.

Lastly, Equation (6) represents the stress traction, or force per area, exerted by muscle forces during mastication on the mandible. Here $n_{j}$ is the $j$ th component of the normal unit vector at a surface point $\mathrm{P}$ and $T_{i}$ is the $i$ th component of traction. The magnitude and direction of muscle forces during the simulated bite were obtained from Korioth ${ }^{12}$ and are shown in Table 3. The data from this reference pertains to the bite of a healthy adult with an intact mandible. It is estimated that the bite force of a patient with a fractured mandible is $60 \%$ of that of a healthy adult ${ }^{18}$. The bite force data was modified accordingly in this study. The muscle attachment areas on the mandible were obtained from Gray ${ }^{11}$. Figure 2 shows the mandibular model with the applied boundary conditions.

\begin{tabular}{|c|c|c|c|c|c|}
\hline \multirow[b]{2}{*}{ Muscle } & \multicolumn{2}{|c|}{ Muscle Weight } & \multicolumn{3}{|c|}{ Force Direction } \\
\hline & $\begin{array}{l}\text { Right/ } \\
\text { Working } \\
\text { Side }\end{array}$ & $\begin{array}{l}\text { Left/ } \\
\text { Balancing } \\
\text { Side }\end{array}$ & $\mathrm{x}$ & $\mathbf{Y}$ & Z \\
\hline Superficial Masseter & 82.3 & 68.5 & -0.21 & 0.89 & 0.42 \\
\hline Deep Masseter & 35.3 & 29.4 & -0.55 & 0.76 & -0.36 \\
\hline Medial Pterygoid & 88.1 & 62.9 & 0.49 & 0.79 & 0.37 \\
\hline Anterior Temporalis & 69.2 & 55.0 & -0.15 & 0.99 & 0.04 \\
\hline Middle Temporalis & 37.9 & 38.4 & -0.22 & 0.84 & -0.50 \\
\hline Posterior Temporalis & 26.8 & 17.7 & -0.21 & 0.47 & -0.86 \\
\hline Inferior Lateral Pterygoid & 12.0 & 26.1 & 0.63 & -0.17 & 0.76 \\
\hline
\end{tabular}

Table 3. Muscle forces for both the working (where the bite occurs) and balancing sides of the mandible. Each muscle force is found by multiplying the muscle weight by the three unit direction vectors and then distributed across the area of attachment. The $\mathrm{X}$ vector is normal to the sagittal plane with the positive direction towards the left side of the mandible. The $\mathrm{Y}$ vector is normal to the occlusal plane with the positive direction pointing superiorly. The $\mathrm{Z}$ direction is orthogonal to the other axes. All muscle force data was taken from Korioth ${ }^{12}$. The original data was scaled at $60 \%$ to represent the bite force of a patient with a healing mandible fracture ${ }^{18}$.

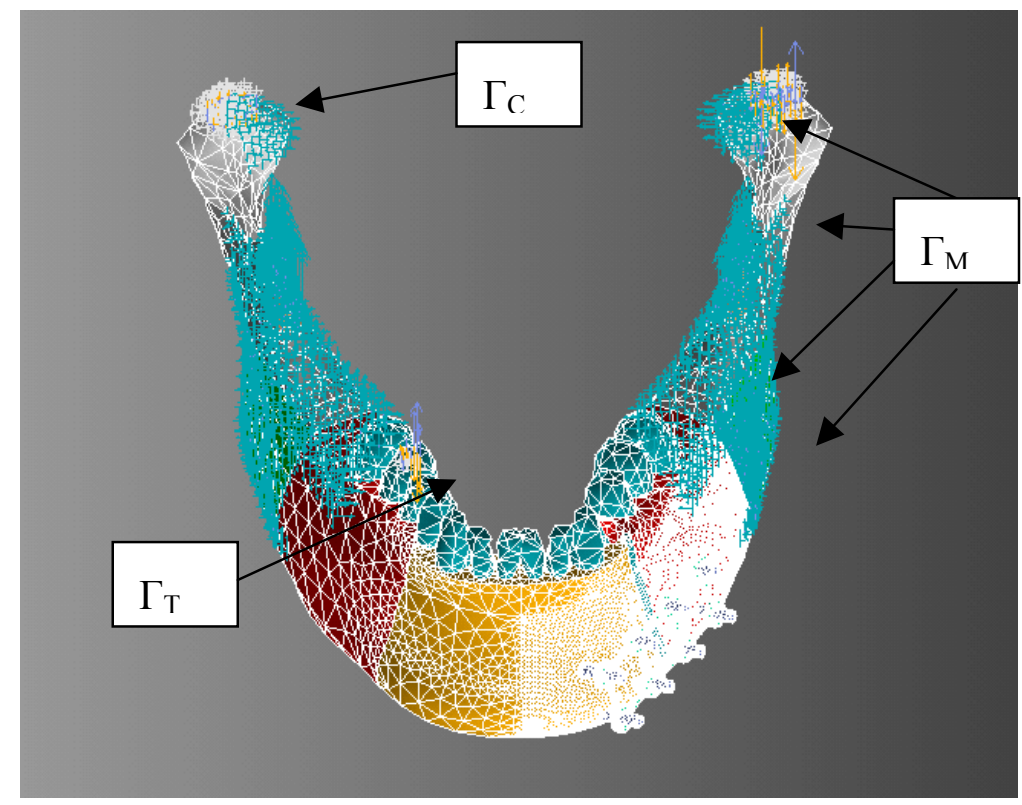

Proceedings of the 2008 ASEE Gulf-Southwest Annual Conference

The University of New Mexico - Albuquerque

Copyright (C) 2008, American Society for Engineering Education 
Figure 2. Boundary conditions applied to the mandibular domain $(\Omega) . \Gamma_{\mathrm{M}}$ represents the masseter, temporalis, medial pterygoid, and lateral pterygoid muscles. $\Gamma_{\mathrm{C}}$ is the condyle area. $\Gamma_{\mathrm{M}}$ and $\Gamma_{\mathrm{C}}$ belong to both sides of the mandible. $\Gamma_{\mathrm{T}}$ is the area on the superior border of the $1^{\text {st }}$ Molar contralateral to the fracture side of the mandible.

\section{Results}

Results for the FE model are shown over the first eight weeks of healing for the following measures: average first principal strain in the fracture region, peak Von Mises stress in the titanium plate, and peak Von Mises stress in the cortical bone surrounding the screws. Results for $1^{\text {st }}$ principal strain in the fracture region were averaged over all elements contained within this region. Figure 3 graphically shows the $1^{\text {st }}$ principal strain of the fracture region in the mandibular model for the analysis simulating immediate post surgery functioning. Higher strains were located on the periphery of the fracture site with higher strains found buccally than lingually. Figure 4 gives the average first principal strain in the fracture, or callus, region over the first eight weeks of healing. It is shown by the figure that first principal strain reduces to $54 \%$ of its immediate postoperative value by week 2 and to $24 \%$ by week 4 . Figure 5 shows the displacements calculated for the whole model in a direction normal to the fracture plane for the analysis simulating immediate post surgery functioning. The deformed shape of the mandible clearly shows tension in the superior region of the fracture with compression near the inferior border.

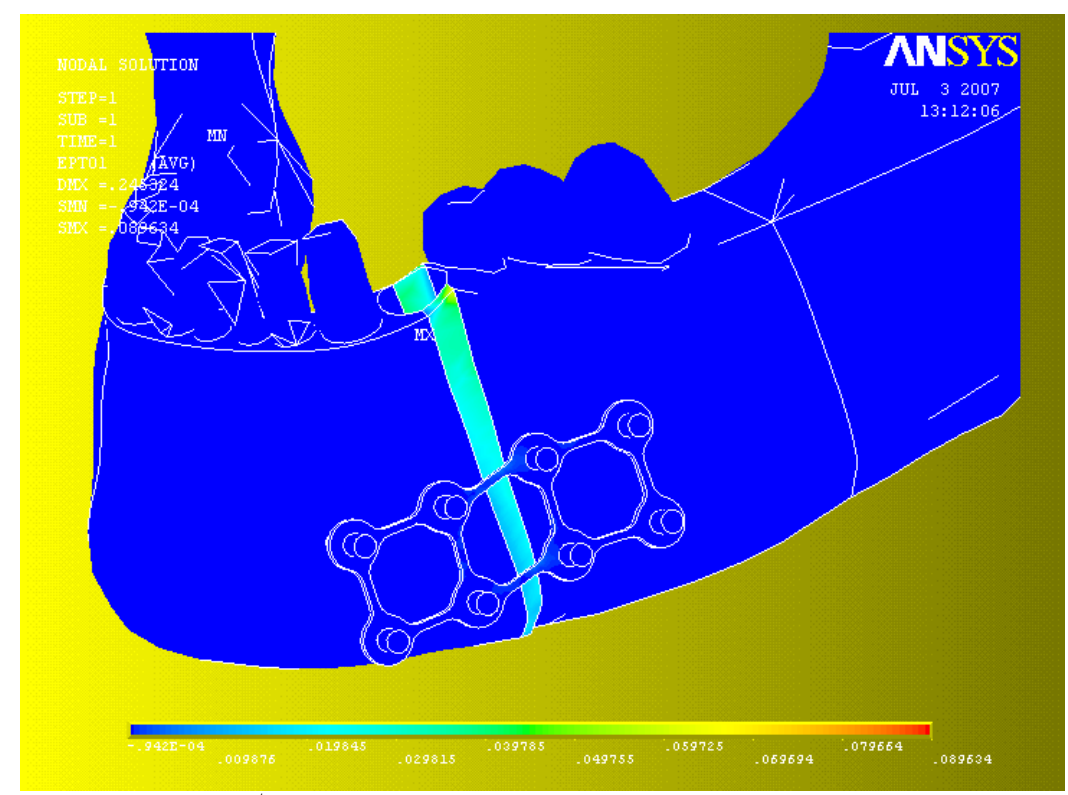

Figure 3. Contours showing $1^{\text {st }}$ Principal strain in the mandibular body, the fixation hardware, and the fracture region of the mandible. The results are for the immediate post-surgery analysis with no healing time before loading. 


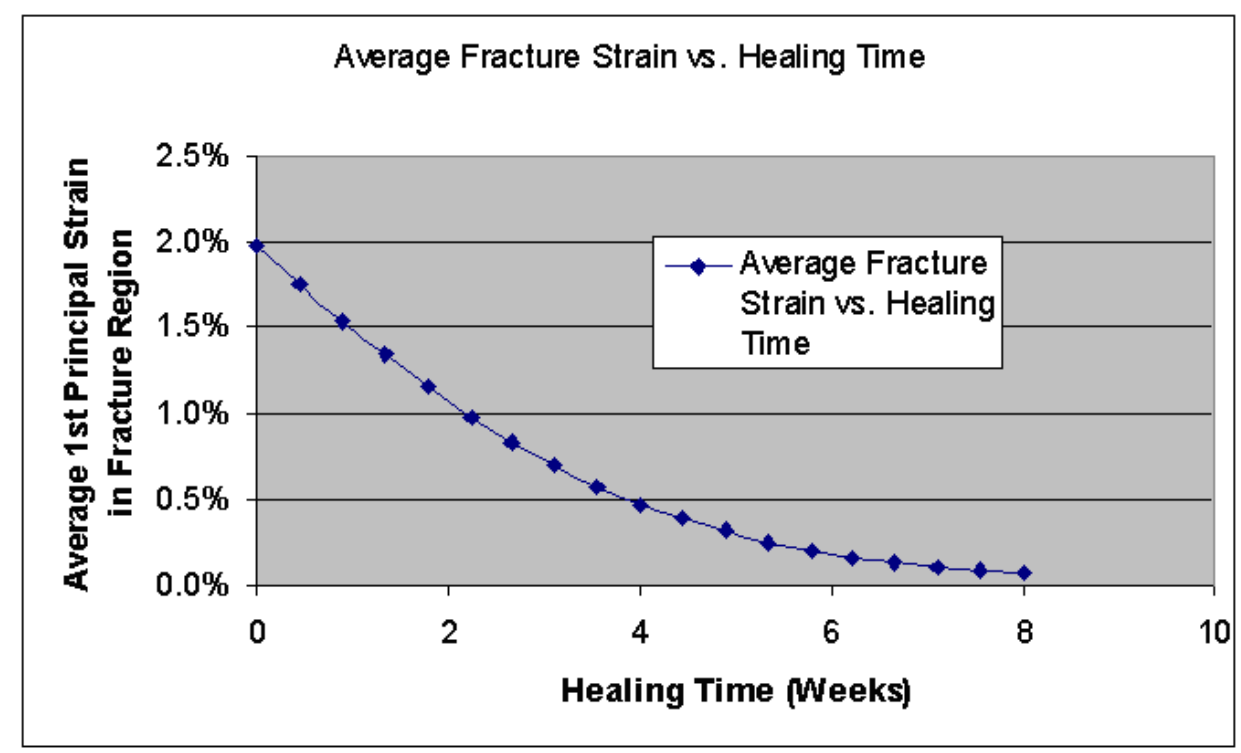

Figure 4. Average first Principal strain in the fracture region over the first eight weeks of healing of a parasymphyseal fracture.

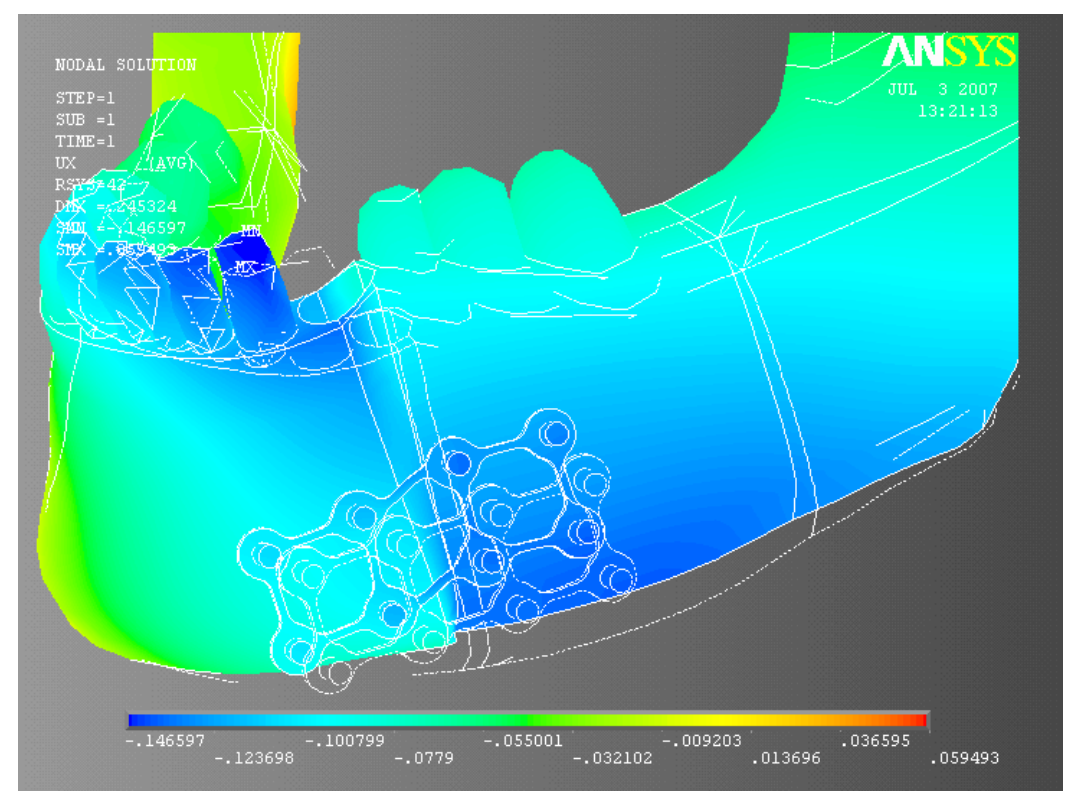

Figure 5. Displacment $(\mathrm{mm})$ shown for the whole mandibular model in loading occurring immediately after surgery. The displacement direction is normal to the fracture plane. The plot shows tension occurring near the superior border of the fracture with compression on the inferior border.

Results are shown for the peak Von Mises stress in the titanium plate over the first eight weeks of healing (Fig. 6). Figure 7 graphically shows the Von Mises stress over the mandibular model for the analysis simulating immediate post surgery functioning. Stress was measured at all nodes along the midplane of the plate thickness and the highest of these stresses was designated the peak value. Higher stress in all analyses was found in the superior medial region of the plate. Titanium plate stress reduces to $60 \%$ of its original value by week 2 and to $30 \%$ by week 4 . 


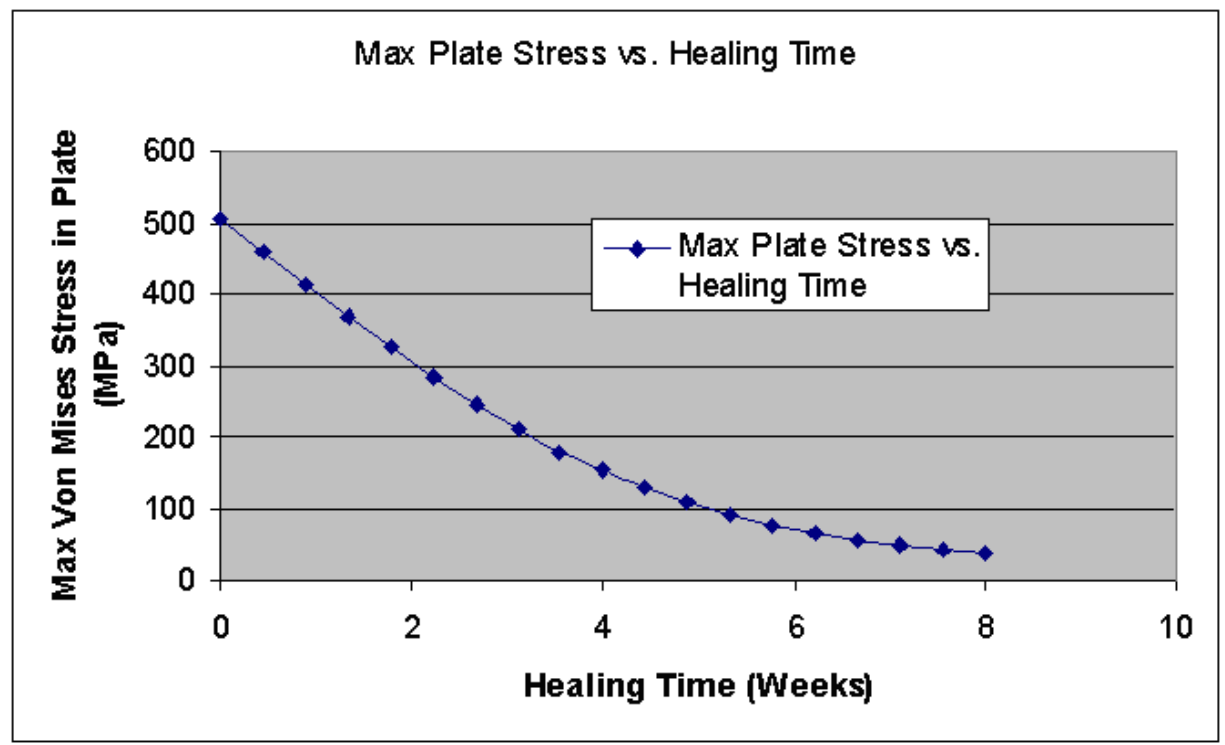

Figure 6. Peak Von Mises stress (MPa) in the titanium plate over the first eight weeks of healing of a parasymphyseal fracture.

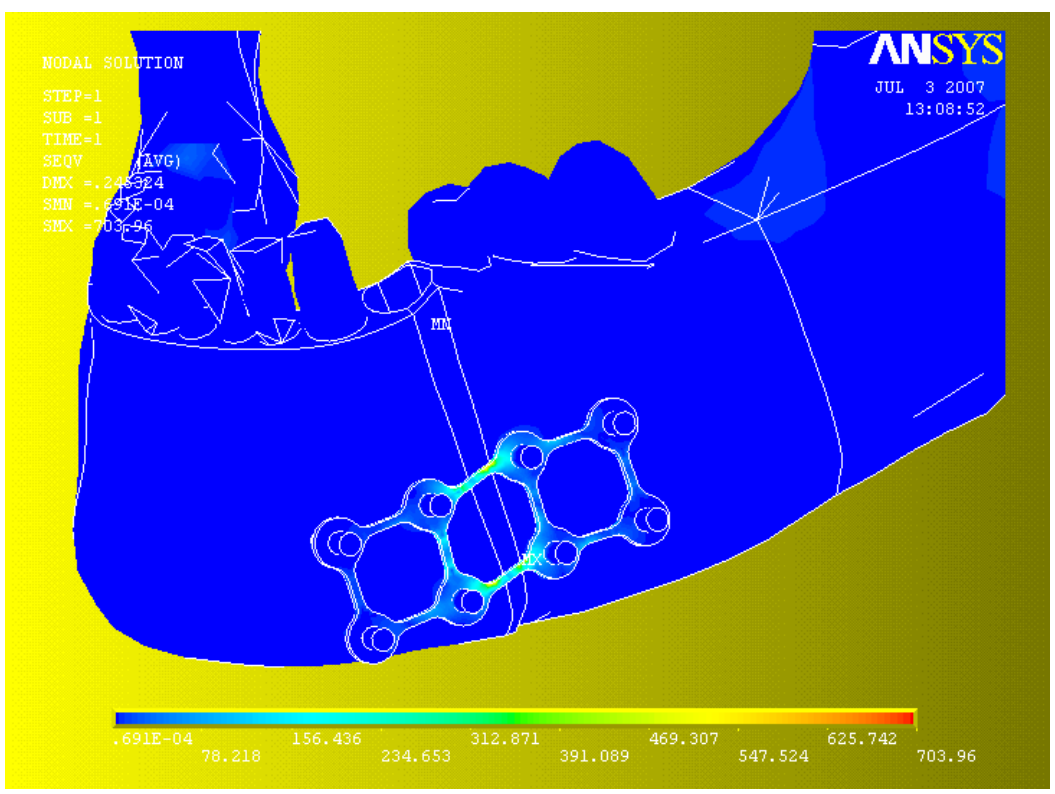

Figure 7. Contours showing the Von Mises stress in the mandibular body and the fixation hardware. The results are for the immediate post-surgery analysis with no healing time before loading.

Results were gathered for the peak Von Mises stress in the cortical bone surrounding the screws over the first eight weeks of healing (Fig. 8). In all analyses, peak stresses occurred on the two superior screws medial to the fracture site. The cortical bone stress is reduced to $62 \%$ of its original value by week 2 and to $31 \%$ of the original value by week 4. 


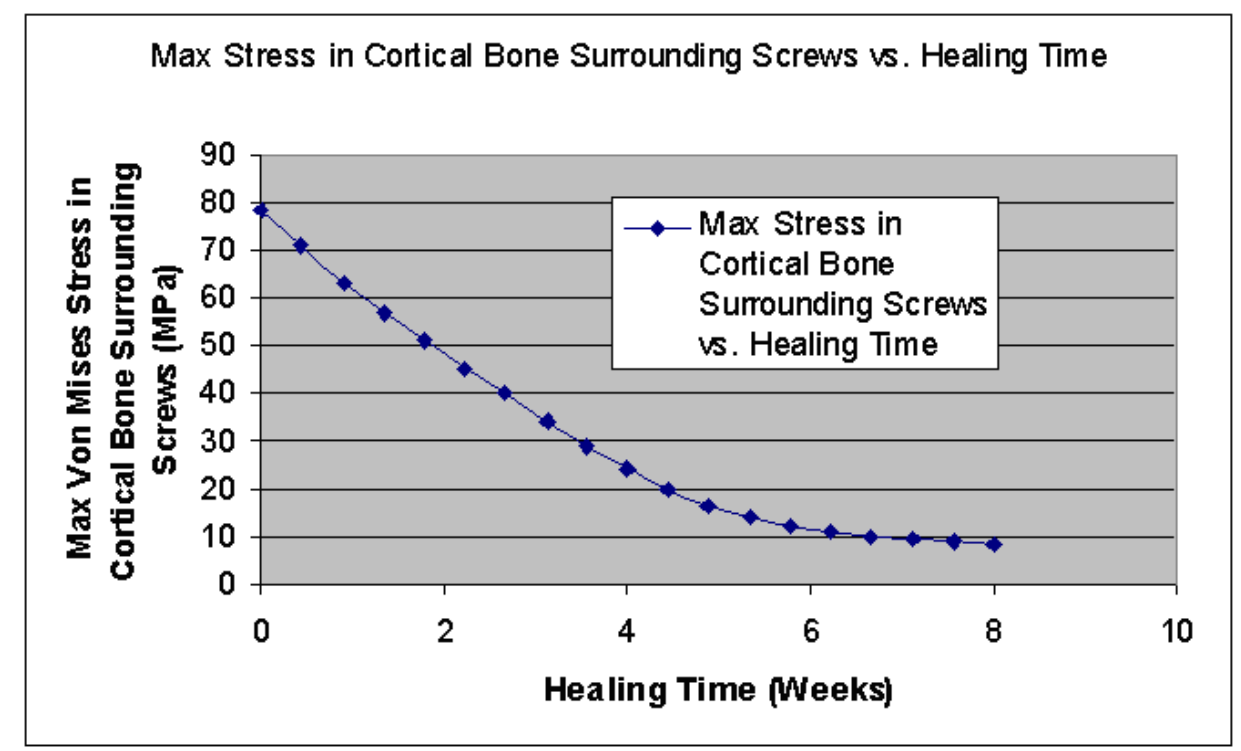

Figure 8. Peak Von Mises stress (MPa) in the cortical bone surrounding the screws over the first eight weeks of healing of a parasymphyseal fracture.

\section{Discussion}

The numerical results show that immediately after surgery the average first principal strain in the callus region is approximately $2.0 \%$, the peak Von Mises stress in the titanium plate is $504 \mathrm{MPa}$, and the peak Von Mises stress in the cortical bone surrounding the screws is $78 \mathrm{MPa}$. The yield strength of Titanium is approximately $1000 \mathrm{MPa}^{6}$ while Frost ${ }^{8}$ reported that strain in the callus/fracture region should be within $0.1 \%$ and $3.0 \%$ to heal appropriately and that screw implants should not induce stresses in bone over 60 $\mathrm{MPa}$. We see that the stress in cortical bone is the only measure that exceeds these limits in this case. We note that this peak stress is over a minute region of the sharp entrant corner of the screw into bone. Given the performance of this type of fixation in the other measures, we conclude that this plate would be appropriate for fixation of a patient with parameters (bone quality, jaw size, bite force, non-comminuted fracture) similar to those of a typical 20 to 40 year old male with a fracture that can be reduced appropriately.

Because of the variability among subjects, the results of these analyses are best viewed qualitatively. This is especially true when translating these results to cases using different hardware. Results for all three measures decrease to $54 \%-62 \%$ of their original values in the first two weeks, decreasing further to $24 \%-31 \%$ of their original values by week 4 . This similar trend continues for all three measures showing asymptotic behavior around week 6 . These results should be a guide towards surgeons pertaining to the option of postoperative IMF and the mastication habits of each patient during the first eight weeks post-operation. Observing the FE results we note that a minimum of 2 weeks of IMF is attractive for any patient and could reduce complications significantly. The continued decrease in stress and strain measures up to 4 weeks after surgery suggests that a soft diet should be used until this point. In some cases of poor bone quality or fracture

\section{Proceedings of the 2008 ASEE Gulf-Southwest Annual Conference \\ The University of New Mexico - Albuquerque \\ Copyright (C) 2008, American Society for Engineering Education}


comminution, IMF could be recommended for the entire 4 week period. The results of FE analyses suggest that soft diet or IMF past six weeks will have little effect on the stress and strain measures examined in this study.

The results of this study are compared to a retrospective study performed on patients treated at the University of New Mexico Hospital (UNMH) between 2000 and 2004 ${ }^{4}$. All patients examined suffered a symphyseal or parasymphyseal fracture and were fixated with a single 3D Matrix miniplate or 2 Low Profile Band miniplates in parallel. All patients also underwent a minimum of two weeks of postoperative IMF. Of the eighty patients reviewed, six (8\%) had postoperative complications. All complications were due to exposed hardware, paresthesia, malocclusion, and TMJ pain. No complications were related to infection, nonunion, delayed union, or failed hardware; complications influenced by the measures examined in this FE study. None of the complications in the retrospective study required plate removal. This is an attractive outcome compared to other retrospective studies of rigid internal fixation of mandibular fractures ${ }^{2,9,13,16}$. The results of this UNMH review corroborates numerical analysis suggesting that a significant decrease in the stress and strain measures leading to patient complications is realized if normal patient functioning is delayed until after two weeks of healing has occurred.

\section{Acknowledgements}

The authors acknowledge the support of Stryker-Leibinger Corp. for a Graduate Fellowship.

\section{References}

1. An YH (2000) Mechanical properties of bone. Mechanical Testing of Bone and the Bone-Implant Interface:41-59 CRC Press LLC.

2. Bhatt V, Langford RJ (2003) Removal of miniplates in maxillofacial surgery: University Hospital Birmingham experience. J Oral Maxillofac Surg 61:553-556.

3. Bolourian R, Lazow S, Berger J (2002) Transoral $2.0 \mathrm{~mm}$ miniplate fixation of mandibular fractures plus 2 weeks' maxillomandibular fixation: a prospective study. J Oral Maxillofac Surg 60:167-170.

4. Boyd N, Wagner JD, Lovald S, Miller T, Baack BR, Kelly J, Khraishi T (2007) Clinical and finite element analysis of low-profile 3D and parallel miniplates in fixation of mandibular symphysis and parasymphysis fractures. Technical Report, University of New Mexico, Dept. of Surgery.

5. Chaudhary N, Lovald S, Wagner J, Khraishi T, Kelly J, Wood J (2004) Modeling of screw-plate systems for mandibular fracture repair. Proceedings of the ASME IMECE2004 conference, Bioengineering Division, paper\# 62256 Anaheim, California 11/13/04-11/19/04.

6. Cox T, Kohn MW, Impelluso T (2003) Computerized analysis of resorbable polymer plates and screws for the rigid fixation of mandibular angle fractures. J Oral Maxillofac Surg 61:481-487.

7. Craig RG, Peyton FA (1958) Elastic and mechanical properties of human dentin. J D Res 37:710-718.

8. Frost HM (2003) A 2003 update of bone physiology and Wolff's law for clinicians. Angle Orthod 74:3-15.

9. Gabrielli MAC, Gabrielli MFR, Marcantonio E, Hochuli-Vieira E (2003) Fixation of mandibular fractures with 2.0-mm miniplates: review of 191 cases. J Oral Maxillofac Surg 61:431-436.

10. Gardner TN, Stoll T, Marks L, Mishra S, Knothe Tate M (2000) The influence of mechanical stimulus on the pattern of tissue differentiation in a long bone fracture - an FEM study. J Biomech 33: 415425.

11. Gray H (1995) Gray's Anatomy, $15^{\text {th }}$ ed. Barnes and Noble Books

12. Korioth TWP, Romilly DP, Hannam AG (1992) Three-dimensional finite element stress analysis of the dentate human mandible. Am J Phys Anthropol 88:69-96. 
13. Lamphier J, Ziccardi V, Ruvo A, Janel M (2003) Complications of mandibular fractures in an urban teaching center. J Oral Maxillofac Surg 61:745-749.

14. Lovald S, Wagner J, Khraishi T, Kelly J, Wood J, Baack B (2006) Comparison of plate-screw systems used in mandibular fracture reduction: finite element analysis. J Biomech Eng 128:654-662.

15. Lovald S, Wagner J, Khraishi T, Kelly J, Wood J, Baack B (2007) Finite element analysis of screwplate systems for fixation of parasymphyseal fractures of the mandible. J Mechanics 23:69-77.

16. Murthy AS, Lehman JA (2005) Symptomatic plate removal in maxillofacial trauma: a review of 76 cases. Ann Plast Surg 55:603-607.

17. Schwartz-Dabney CL, Dechow PC (2003) Variations in cortical material properties throughout the human dentate mandible. Am J Phys Anthropol 120:252-277.

18. Tate GS, Ellis E III, Throckmorton G (1994) Bite forces in patients treated for mandibular angle fractures. J Oral Maxillofac Surg 54:734-736.

19. Wagner A, Krach W, Schicho K, Undt G, Ploder O, Ewers R (2002) A 3-dimensional finite-element analysis investigating the biomechanical behavior of the mandible and plate osteosynthesis in cases of fractures of the condylar process. Oral Surg Oral Med Oral Pathol Oral Radiol Endod 94:678-686.

\section{SCOTT LOVALD}

Scott Lovald received a BSME, MEME, and MBA from the University of New Mexico. Scott has been the recipient of a number of awards and research fellowships focused in the design and analysis of medical implants using the finite element method and computational fluid dynamics. Over the past five years, he has been involved in a number of projects and publications pertaining to craniomaxillofacial implant design including working with Stryker-Leibinger in Freiburg, Germany. Scott is currently pursuing a $\mathrm{PhD}$ in Mechanical Engineering at the University of New Mexico.

\section{TARIQ KHRAISHI}

Dr. Khraishi currently serves as an Associate Professor of Mechanical Engineering at the University of New Mexico. His general research interests are in theoretical, computational and experimental solid mechanics and materials science. He has taught classes in Dynamics, Materials Science, Advanced Mechanics of Materials, Elasticity and Numerical Methods. For the last four years he has engaged himself in the scholarship of teaching and learning.

\section{JON WAGNER}

Dr. Jon Wagner MD DDS attended the University of Missouri's School of Dentistry from 1980-1984 and graduated with distinction, then served as a resident in department of Oral and Maxillofacial Surgery at the Truman Medical Center in Kansas City, Missouri. Dr. Wagner became a Doctor of Medicine in 1989 graduating from the University of Missouri's School of Medicine. He then completed his fellowship in Maxillofacial Trauma at UNMH in 1991 and is currently Director of Maxillofacial Trauma and Head of Plastic Surgery at University of New Mexico Health Center. He is well published in the area of craniomaxillofacial fracture fixation.

\section{BRET BAACK}

Dr. Bret R. Baack received a B.S. degree in Chemistry and a B.A. degree in Biology from the University of New Mexico. He attended the University of New Mexico Medical School, and completed a fellowship in Burn Reconstruction and Plastic Surgery from Southern Illinois University. He has been at the University of New Mexico Hospital since 1990, and currently serves as the Chief of Plastic Surgery. Special interests include maxillofacial and breast reconstruction following tumor extirpation. 